\title{
Interpretación del art. 34 inc. 1 del Código Penal Argentino a la luz de la Ley Nacional de Salud Mental. Consecuencias. La situación de las personas con declaración de inimputabilidad en la Provincia de Buenos Aires
}

\author{
Por Rios Santiago Rodolfo
}

\section{Resumen}

La Ley Nacional de Salud Mental -en adelante LSM- resulta aplicable a los supuestos contemplados en el. Art. 34 inc. 1 del Código Penal Argentino -en adelante CP.

Dado el carácter posterior y especial de la referida ley respecto al CP, este debe interpretarse a la luz de aquella. Esto repercute en que las medidas del art. 34 inc. 1 del CP deben:

-Ser entendidas como internaciones involuntarias de la LSM con finalidad exclusivamente terapéutica, por ende, debe adoptarse al riesgo cierto e inminente como criterio para determinarlas -ya no debe utilizarse el concepto de peligrosidad-.

-Ejecutarse, en principio, en hospitales generales -nunca en unidades penitenciarias-

-Desarrollarse de la manera menos restrictiva de derechos posible y durar el menor tiempo posible según las necesidades terapéuticas del caso -en virtud del principio "opción menos restrictiva"-. Límite temporal que además tiene por techo la proporcionalidad que debe guardar la internación/medida con la pena que se hubiera impuesto de no mediar declaración de inimputabilidad.

El contraste de esos estándares con los datos que se han recabado de las personas con declaración de inimputabilidad en la provincia de Buenos Aires, evidencia una falta de concreción de los mismos que se ve reflejada en:

-Alojamiento de personas con padecimientos mentales en unidades penitenciarias.

-Supuestos donde se mantiene las internaciones: a) sin mediar criterio de internación en razón de problemáticas de tipo social, y/o b) por periodos de tiempo que resultan desproporcionados en relación a la pena que podría haberse impuesto de no haber mediado declaración de inimputabilidad. 


\section{a.-Aplicación de la LSM a los supuestos contemplados en el art. 34 inc 1 del CP. Pauta interpretativa}

La Ley Nacional de Salud Mental ${ }^{1}$ introduce en el ordenamiento nacional un cambio de paradigmas $^{2}$ que repercute en todas las esferas del estado y de la sociedad civil involucradas en la temática -salud mental-. Siendo las cosas así, huelga decir que la misma resulta aplicable no solo en el fuero civil sino también en el penal.

Empero, lamentablemente la LSM no fue tan clara al determinar su aplicación a los supuestos alcanzados por el art. 34 inc. 1 del $\mathrm{CP}^{3}$, como sí lo fue en relación a su aplicación al fuero civil ya que, mientras que dedica dos disposiciones complementarias a modificar expresamente el Código Civil a fin de adecuarlo a su texto, sólo menciona al Código Penal en una sola oportunidad y en forma tangencial -art. 23 de la LSM-. Lo cual, torna necesario comenzar el presente realizando algunas disquisiciones en torno a la aplicación de la mencionada ley al ámbito penal.

La aplicación de la LSM a dicha órbita y particularmente a los supuestos comprendidos en el art. 34 inc. 1 del CP surge del carácter general con el que en la misma se determina su objeto y su ámbito de aplicación en sus artículos 1 y $6^{4}$ respectivamente. Por otro lado, si a

1 Ley 26657. Sancionada: Noviembre 25 de 2010 Promulgada: Diciembre 2 de 2010

2 Respecto a dicho cambio de paradigmas se ha manifestado: "La LSM puede ser leída en diferentes recorridos, congruentes entre si: - Desde el paradigma de la peligrosidad hacia el paradigma de la capacidad. - Desde un enfoque tutelar hacia un enfoque de derechos - Desde un proyecto de exclusión hacia un proyecto de inclusión" Rodríguez, José Antonio, "Comentarios a la ley de salud mental" (Profesor de la Cat. II de Psicología Jurídica de la UBA)-pag 2-. Documento Digital:

http://www.bibliopsi.org/docs/materias/obligatorias/CFP/juridica/sarmiento/rodriguez\%20-

\%20comentarios\%20a\%20la\%20ley\%2026657.pdf

3 CP. Art. 34.- No son punibles: 1. El que no haya podido en el momento del hecho, ya sea por insuficiencia de sus facultades, por alteraciones morbosas de las mismas o por su estado de inconciencia, error o ignorancia de hecho no imputables, comprender la criminalidad del acto o dirigir sus acciones. En caso de enajenación, el tribunal podrá ordenar la reclusión del agente en un manicomio, del que no saldrá sino por resolución judicial, con audiencia del ministerio público y previo dictamen de peritos que declaren desaparecido el peligro de que el enfermo se dañe a sí mismo o a los demás. En los demás casos en que se absolviere a un procesado por las causales del presente inciso, el tribunal ordenará la reclusión del mismo en un establecimiento adecuado hasta que se comprobase la desaparición de las condiciones que le hicieren peligroso;

4 LSM. Art. 1: La presente ley tiene por objeto asegurar el derecho a la protección de la salud mental de todas las personas, y el pleno goce de los derechos humanos de aquellas con padecimiento mental que se encuentran en el territorio nacional, reconocidos en los instrumentos internacionales de derechos humanos, con jerarquía constitucional, sin perjuicio de las regulaciones más beneficiosas que para la protección de estos derechos puedan establecer las provincias y la Ciudad Autónoma de Buenos Aires. LSM. Art. 6: Los servicios y efectores de salud públicos y privados, cualquiera sea la forma jurídica que tengan, deben adecuarse a los principios establecidos en la presente ley. 
pesar de la claridad de dichos artículos persiste alguna duda al respecto, esta debe ceder ante lo previsto en el artículo 23 de la citada ley ${ }^{5}$ entendido a contrario sensu.

Efectivamente, interpretando a contrario sensu dicha norma, es imperioso concluir que si la regla contenida en el art. 23 - "externación automática"- no es aplicable a los sujetos contemplados en el art. 34 del CP y fue necesario contemplar esa excepción expresamente. Debe inferirse que el resto de la LSM, si es aplicable a las personas que se encuentran dentro de las previsiones del mentado artículo del CP. En este sentido -aunque arribando a esta conclusión por otra vía- manifiesta Marcelo B. Martínez (2015) debe interpretarse que las personas internadas en el marco de una medida de seguridad, gozan en forma íntegra de todos los derechos establecidos por la ley de salud mental." También refuerza lo dicho el decreto reglamentario de la LSM -Decreto 603/2013- al hacer referencia expresa al art. 34 inc. 1 del CP, estableciendo en cabeza de la Autoridad de Aplicación de la LSM -Ministerio de Salud-, el deber de promover la creación de dispositivos intermedios destinados a alojar a personas alcanzadas por dicho artículo del $\mathrm{CP}^{6}$

Habiendo dejado en claro que la LSM resulta aplicable a los supuestos comprendidos en el Art. 34 inc. 1 del CP y teniendo en cuenta que la primera es una ley posterior y especial se impone señalar que ante cualquier conflicto entre ambas normas o superposición de objetos, ésta -la LSM- debe primar por sobre la letra del CP. Por ello, en el presente trabajo se realizará un esfuerzo por interpretar al CP a la luz de lo normado en la LSM y no lo contrario.

\section{b.-Consecuencias de la aplicación}

Partiendo de la aplicación señalada y de la pauta interpretativa propuesta, se analizará en qué forma la LSM impacta en muchos de los principales aspectos de las llamadas "medidas de seguridad”. A fin de tornar más sencillo ese análisis se denominará cada uno de esos aspectos que se ven afectados con una pregunta. En ese sentido, se relevará: 1) qué debe entenderse por lo que suele denominarse "medida de seguridad", 2) cuando están dadas las condiciones para aplicarla, 3) donde deben ejecutarse y, por último, 4) cómo y por cuanto deben ejecutarse.

5 LSM. Art. 23: El alta, externación o permisos de salida son facultad del equipo de salud que no requiere autorización del juez. El mismo deberá ser informado si se tratase de una internación involuntaria, o voluntaria ya informada en los términos de los artículos 18 ó 26 de la presente ley. El equipo de salud está obligado a externar a la persona o transformar la internación en voluntaria, cumpliendo los requisitos establecidos en el artículo 16 apenas cesa la situación de riesgo cierto e inminente. Queda exceptuado de lo dispuesto en el presente artículo, las internaciones realizadas en el marco de lo previsto en el artículo 34 del Código Penal.(el resaltado es propio)

6 Decreto 603 de 2013. Regulación del art. 11 de la LSM: "La Autoridad de Aplicación promoverá que la creación de los dispositivos comunitarios, ya sean ambulatorios o de internación, que se creen en cumplimiento de los principios establecidos en la Ley, incluyan entre su población destinataria a las personas alcanzadas por el inciso 1) del artículo 34 del Código Penal, y a la población privada de su libertad en el marco de procesos penales." 


\section{b.1. “El Quê”. (internación involuntaria/recurso terapeútico)}

Retomando la lectura del art. 23 de la LSM-, puede extraerse otra conclusión -además de la aplicación de dicha ley al ámbito penal-: Si el art. 23 de la LSM hace referencia a las medidas del art. 34 del CP diciendo "...las internaciones realizadas en el marco del art. 34 del CP..." -el resaltado es propio-, se impone entender que dichas medidas, al menos en principio, son internaciones. Además, si a ello le sumamos la ubicación del mencionado artículo dentro de la ley, es decir, se encuentra bajo el título "internaciones" y entre las disposiciones destinadas a las internaciones involuntarias, se torna imperioso entender que tanto la reclusión en un manicomio como la reclusión en un establecimiento adecuado mencionadas en el artículo 34 del inc 1 párrafos 2 y 3 del $\mathrm{CP}^{7}$, a la luz de la LSM deben deben ceder para pasar a ser entendidas como internaciones involuntarias.

Teniendo en cuenta lo mencionado anteriormente, debe entenderse que las referidas medidas/internaciones involuntarias, deben ser consideradas como un recurso terapeútico conforme establece la LSM en sus arts. 14 y $20^{8}$, es decir, como un medio destinado a tratar los padecimientos mentales del internado.

Lo señalado va de la mano con lo establecido en los "Principios de Naciones Unidas para la Protección de los Enfermos Mentales y para el Mejoramiento de la Atención de Salud Mental", puntualmente en el principio $16^{9}$, en donde también se remarca el carácter terapéutico de la internación involuntaria y con lo establecido por la CSJN en el precedente "R. M. J. s/ insania. (Competencia $N^{\circ}$ 1195. XLII.)" del $2008^{10}$.

7 Art. 34 inc1 párf. 2 y 3 del CP: En caso de enajenación, el tribunal podrá ordenar la reclusión del agente en un manicomio, del que no saldrá sino por resolución judicial, con audiencia del ministerio público y previo dictamen de peritos que declaren desaparecido el peligro de que el enfermo se dañe a sí mismo o a los demás.

En los demás casos en que se absolviere a un procesado por las causales del presente inciso, el tribunal ordenará la reclusión del mismo en un establecimiento adecuado hasta que se comprobase la desaparición de las condiciones que le hicieren peligroso

8 LSM. Art 20: "La internación involuntaria de una persona debe concebirse como recurso terapéutico..."; Art. 14: "La internación es considerada como un recurso terapéutico..."

9 Principios de Naciones Unidas para la Protección de los Enfermos Mentales y para el Mejoramiento de la Atención de Salud Mental .Principio 16 Admisión involuntaria. 1. Una persona sólo podrá ser admitida como paciente involuntario en una institución psiquiátrica o ser retenida como paciente involuntario en una institución psiquiátrica a la que ya hubiera sido admitida como paciente voluntario cuando un médico calificado y autorizado por ley a esos efectos determine, de conformidad con el principio 4 supra, que esa persona padece una enfermedad mental y considere: a) Que debido a esa enfermedad mental existe un riesgo grave de daño inmediato o inminente para esa persona o para terceros; b) Que, en el caso de una persona cuya enfermedad mental sea grave y cuya capacidad de juicio esté afectada, el hecho de que no se la admita o retenga puede llevar a un deterioro considerable de su condición o impedir que se le proporcione un tratamiento adecuado que sólo puede aplicarse si se admite al paciente en una institución psiquiátrica de conformidad con el principio de la opción menos restrictiva.

10 En dicho fallo la CSJN manifestó: "Toda internación involuntaria en los distintos supuestos en que un juez puede disponer un encierro forzoso debe, a la luz de la normativa vigente, sustentarse exclusivamente en el padecimiento de una afección mental susceptible de internación en tanto, en un contexto terapéutico, 
En resumen, a la luz de la LSM debe entenderse que las llamadas "medidas de seguridad" del art. 34 inc. 1 del CP, son internaciones involuntarias -reguladas en la LSM-y como tales su razón de ser ya no radica en proteger a la sociedad frente a un sujeto peligroso, sino en su finalidad terapeútica.

Por último, debe destacarse que al concluir que se trata de internaciones involuntarias se tornan aplicables todos los estándares que establece la LSM a las mismas -salvo por la referida excepción del art. 23 de la LSM- ya que con ello en mente se realizarán los desarrollos de los siguientes puntos de este apartado.

\section{b.2. "El cuándo" (Criterio de internación y determinación del mismo)}

El CP estableció históricamente a la "peligrosidad" como criterio para determinar la posibilidad de aplicar una "medida" del Art. 34 de CP. Dicho concepto que "...proviene del concepto de "temibilidad" acuñado por Garófalo..." resulta sumamente vago e impreciso ${ }^{12}$. Por ello ha sufrido grandes adaptaciones e interpretaciones a lo largo de la historia ${ }^{13}$. Sin embargo, hoy a la luz de las pautas interpretativas dadas, el mismo debe ceder ante el concepto de riesgo cierto o inminente que establece la LSM como criterio para determinar una internación involuntaria en su art. 2014. Este concepto resulta particularmente preciso en virtud de la regulación que de dicho artículo hace el Decreto Reglamentario de la LSM 603/2013- que reza: "Entiéndase por riesgo cierto e inminente a aquella contingencia o proximidad de un daño que ya es conocido como verdadero, seguro e indubitable que amenace o cause perjuicio a la vida o integridad física de la persona o de terceros...".

Como puede verse, no se trata de cualquier riesgo sino de un riesgo calificado, no solo en torno a su pronóstico -verdadero, seguro e indubitable- sino también en torno a los bienes que deben estar amenazados -vida e integridad física- y en cuanto a su temporalidad -inminente-.

represente la posibilidad de evitar que se concreten actos dañosos graves, inmediatos o inminentes para esa persona o para terceros (Principios de Salud Mental, 16. 1. a) o bien que la terapéutica requiera ineludiblemente el aislamiento del paciente durante algún tiempo. De este modo, la razonabilidad de la internación depende de su legitimación."

11 Martínez B. Marcelo "Derecho y Salud Mental”;editorial Juris; 2015, pág. 133.-

12 Vale mencionar que en la práctica solía inferirse basándose casi con exclusividad en la categoría diagnóstica.

13 Con referencia las distintas interpretaciones y contenidos que a lo largo de la historia se le dió al concepto de peligrosidad ver Martínez B. Marcelo "Derecho y Salud Mental”;editorial Juris; 2015, pág. 133 a 138.

14 LSM. Art. 20: La internación involuntaria (...) sólo podrá realizarse cuando a criterio del equipo de salud si mediare situación de riesgo cierto e inminente para sí o para terceros. 
A lo dicho hay que sumarle que solo un equipo interdisciplinario podrá determinar dicho riesgo y que no puede presumirse de la sola clasificación diagnóstica conforme surge del mentado decreto reglamentario y del art. 5 de la LSM ${ }^{15}$.

\section{b.3.- "El dónde" (Institución adecuada. Prohibición de alojar en cárceles):}

El CP estableció históricamente que las medidas del art. 34 inc 1, segundo párrafo deben desarrollarse en un manicomio ${ }^{16}$, en otros términos, en un hospital monovalente neuropsiquiátrico-. Mientras que para las del art. 34 inc. 1 párr. 2 del $\mathrm{CP}^{17}$ estaba previsto su desarrollo en un establecimiento adecuado. Es decir, esa norma en ningún punto disponía -ni dispone- que las "medidas" -hoy internaciones- debían ejecutarse en cárceles.

Ahora bien, si se mira estas previsiones a la luz de la LSM debe concluirse que, de conformidad con lo que dicha ley establece en su Art. 28, "Las internaciones de salud mental deben realizarse en hospitales generales..." -el resaltado es propio-, lo cual encuentra correspondencia con el proceso de desmanicomialización que la misma motoriza mediante su art. $27^{18}$.

Vale decir que estas previsiones también resultan congruentes con lo establecido en las "Reglas Mandela" -Reglas Mínimas de las Naciones Unidas para el Tratamiento de los Reclusos", adoptadas por la Asamblea de las N.U. el 17 de diciembre de 2015-, toda vez que la regla 109 punto 1 reza: "No deberán permanecer en prisión las personas a quienes no se considere penalmente responsables o a quienes se diagnostique una discapacidad o enfermedad mental grave, cuyo estado pudiera agravarse en prisión, y se procurará trasladar a esas personas a centros de salud mental lo antes posible."-el resaltado es propio-.

Habiendo dejado sentado lo dicho, pueden existir dudas en torno al alcance o, si se quiere, la fuerza que puede dársele las referidas "Reglas Mandela", en tanto forman parte del llamado "derecho blando", empero, en sentido contrario, es necesario resaltar que dichas normas han sido utilizadas en numerosas oportunidades por la Corte IDH a fin de establecer el alcance que debe dársele a distintas normas de jerarquía convencional, ergo, en esa medida, las citadas reglas pasan a tener fuerza vinculante ${ }^{19}$. Por último, no sobra destacar que la Corte Suprema

15 LSM. Art. 5: "la existencia de diagnóstico en el campo de la salud mental no autoriza en ningún caso a presumir riesgo de daño(...), lo que sólo puede deducirse a partir de una evaluación interdisciplinaria de cada situación en un momento determinado"

16 Art. 34 inc. 1 párf. 2 del CP: "En caso de enajenación, el tribunal podrá ordenar la reclusión del agente en un manicomio...2

17 Art. 34 inc. 1 párf. 2 del CP: "En los demás casos en que se absolviere a un procesado por las causales del presente inciso, el tribunal ordenará la reclusión del mismo en un establecimiento adecuado...”

18 LSM. Art. 27: Queda prohibida por la presente ley la creación de nuevos manicomios, neuropsiquiátricos o instituciones de internación monovalentes, públicos o privados. En el caso de los ya existentes se deben adaptar a los objetivos y principios expuestos, hasta su sustitución definitiva por los dispositivos alternativos. Esta adaptación y sustitución en ningún caso puede significar reducción de personal ni merma en los derechos adquiridos de los mismos.

19 Confr. "Instituto de Reeducación del Menor" Vs. Paraguay" Sentencia de 2 de septiembre de 2004. párf. 154; "DÍAZ PEÑA VS. VENEZUELA" Sentencia de 26 de junio de 2012. párf. 135; "Yvon Neptune vs. Haiti" 
de Justicia de la Nación Argentina también hizo uso de las "Reglas Mínimas" en el sentido señalado en el precedente "Verbitsky, Horacio s/ habeas corpus" (CSJN: Fallos: 328:1146) ${ }^{20}$

\section{b.4.- "El cómo"y "El cuánto". (principio opción menos restrictiva y proporcionalidad)}

b.4.1. El Principio "opción menos restrictiva":_La LSM tanto en su articulado ${ }^{21}$ como a través de las normas del derecho internacional a las que les da jerarquía legal mediante su art. $2^{22}$, establece el principio "opción menos restrictiva”.

En virtud de ese principio la internación involuntaria -y en líneas generales cualquier tratamiento al que se someta en forma involuntaria a una persona con padecimientos mentales- debe ser lo más restrictiva posible tanto desde un punto de vista cuantitativo como cualitativo, en razón del padecimiento. En otros términos, la medida debe durar lo menos posible y restringir la menor cantidad derechos, en función de las necesidades terapéuticas y a fin de neutralizar el referido riesgo.

En relación al mismo manifestó la CSJN: “..De resolverse la implementación de una medida de internación, ésta debe durar el tiempo minimo e indispensable, en razón de ser un tratamiento restrictivo que debe presentarse como última opción (...), dejando sentada la regla de la libertad del paciente...." 23

Este principio presenta tal robustez que en ciertas ocasiones llega incluso a neutralizar algunas de las pautas dadas en los anteriores apartados. Puntualmente, lo que sucede es que el art. 20 inc. $b^{24}$ de la LSM habilita que aún mediando riesgo cierto e inminente -criterio de

Sentencia de 6 mayo de 2008 párf. 131.; "MENDOZA Y OTROS VS. ARGENTINA" -Sentencia del 14 de mayo de 2013- párf. 189, etc. Vale destacar que en estos casos se hace referencia a las "Reglas Mínimas para el Tratamiento de los Reclusos" de 1955 y no las "Reglas Mandela" propiamente dichas, empero, teniendo en cuenta que estas últimas no son más que una actualización de las primeras, de todos modos estos precedente resultan aplicables, al menos, de la forma señalada.

$20 \mathrm{Al}$ respecto vale la misma aclaración realizada en la anterior nota al pie.

21 La LSM establece el principio opción menos restrictiva en sus Arts: 7 d), 14, 15 y 20

22 En este sentido corresponde destacar dentro de las normas citadas en el art. 2 de la LSM, a los Principios de Naciones Unidas para la Protección de los Enfermos Mentales y para el Mejoramiento de la Atención de Salud Mental, toda vez que los mismos consagran en diversas partes de su articulado el mencionado principio y particularmente, al principio 1.7 donde se encuentra su formulación más genérica. Al que debe agregársele los principios 1.7, 9.1, 15.1 y 16 donde se pueden ver manifestaciones particulares del mismo.

23 CSJN: R. M. J. s/ insania. (Competencia N²1195. XLII.).

24 LSM Art. 20. - La internación involuntaria de una persona debe concebirse como recurso terapéutico excepcional en caso de que no sean posibles los abordajes ambulatorios, y sólo podrá realizarse cuando a criterio del equipo de salud mediare situación de riesgo cierto e inminente para sí o para terceros. Para que proceda la internación involuntaria, además de los requisitos comunes a toda internación, debe hacerse constar: a) Dictamen profesional del servicio asistencial que realice la internación. Se debe determinar la situación de riesgo cierto e inminente a que hace referencia el primer párrafo de este artículo, con la firma de dos profesionales de diferentes disciplinas, que no tengan relación de parentesco, amistad o vínculos económicos con la persona, uno de los cuales deberá ser psicólogo o médico psiquiatra; b) Ausencia de otra alternativa eficaz para su tratamiento; c) Informe acerca de las instancias previas implementadas si las hubiera. 
internación- no puede disponerse la internación de existir “...otra alternativa eficaz para su tratamiento...”, es decir, para neutralizar dicho riesgo y asegurar los fines tratamentales. Como puede verse, en este caso, el respeto al principio "opción menos restrictiva" opera neutralizando las pautas dadas al tratar el "cuándo" -criterio de internación- y el "dónde" institución adecuada-.

De hecho, este estándar también fue establecido por la CSJN en el citado precedente "RMJ" al decir: "...no resulta indispensable que la persona deje de ser considerada peligrosa sino que debiera alcanzar con que la internación no sea entendida como el único medio terapéutico disponible, ya sea porque se cuenta con nuevos medios para contenerla o bien porque el estado de peligrosidad no fuera constatación fehaciente mediante lo suficientemente grave o inminente...". Vale destacar que si bien la terminología del mismo no se condice con las pautas aquí dadas, en la medida que habla de peligrosidad, lo cierto es que dicho fallo es anterior al dictado de la LSM-.

Para terminar es necesario destacar que Recientemente el Comité de DDHH de NU, instó la aplicación de dicho principio en el territorio nacional en las "Observaciones finales sobre el quinto informe periódico de la Argentina”; año 2016. Versión avanzada no editada. Párr. 22. Al decir:

El Estado parte debe velar por la plena aplicación de los estándares internacionales y de la Ley Nacional de Salud Mental 26.657. Debe, asimismo, asegurar que toda decisión de recurrir a medios de restricción o internamiento involuntario sea excepcional y vaya precedida de una evaluación médica completa y profesional que determine la restricción estrictamente necesaria que debe aplicarse a un paciente y el tiempo estrictamente necesario -el resaltado es propio-(Comité de DDHH de Naciones Unidas, 2016: 22)

b.4.2. La proporcionalidad: Por otro lado, tratándose de internaciones involuntarias dictadas en sede penal, debe añadirse otro límite temporal. Este límite que recae sobre el tiempo máximo en que la medida puede continuar en sede penal, es de creación pretoriana y se funda en la proporcionalidad. Veamos:

La necesidad de establecer un plazo máximo de duración de las medidas de seguridad dictadas en razón del art. 34 inc. 1 del CP fue esbozada en primer lugar en el precedente de la CSJN “R. M. J. s/ insania. (Competencia N 1195. XLII.)"en el que se estableció:

M. J. R. ha permanecido privado de su libertad, de manera coactiva, más tiempo incluso del que le habría correspondido in abstracto en el supuesto de haber sido condenado a cumplir el máximo de la pena previsto para el delito cometido, a la luz del instituto de la libertad condicional. En estas condiciones, tanto el principio de proporcionalidad como el propósito de respetar el principio de igualdad, que se buscó con la declaración de inimputabilidad, se ven seriamente comprometidos debido a que se muestra como irrazonable que una persona, a la que el Estado no quiere castigar, se vea afectada en sus derechos en una medida mayor de la que le hubiese 
correspondido de haber sido eventualmente condenada como autor responsable. (el resaltado es propio).

Y, luego, -con posterioridad a la sanción de la LSM-, dicho límite fue establecido con mayor precisión en el precedente de la CSJN "Antuña, Guillermo Javier s/ causa n 12.434. (A. 987. XLVI)", en donde, haciendo expresa referencia a la doctrina establecida en "R.M.J.", citada ut supra, se manifestó:

La persona declarada incapaz de culpabilidad tiene un derecho igual al del condenado como autor responsable a conocer con anticipación el plazo máximo por el que podrá extenderse su privación de la libertad -su privación de la libertad, esto es, en aplicación del artículo 34, inciso 1, segundo párrafo, del Código Penal-o Así, el tribunal que dispone una medida de seguridad de naturaleza penal debe fijar el plazo máximo hasta el que la medida podrá extenderse, asegurando una razonable proporcionalidad entre el ilícito cometido y la medida ordenada, como la que aseguraría al limitar la pena que sería aplicable al caso si el imputado no fuera incapaz de culpabilidad. Entiendo, por ello, que la disposición de una internación coactiva, como la confirmada en el pronunciamiento apelado, sin la indicación de su limite temporal máximo contraviene la doctrina de V.E. expuesta en el considerando 14 del precedente de Fallos: 331:211" (el resaltado es propio).

De conformidad con lo que surge de los estándares citados la internación -mal llamada medida- de naturaleza penal solo podrá mantener ese carácter -penal- hasta cumplir con un tiempo igual a la pena que se le hubiese impuesto a la persona en caso de no resultar inimputable. A esos fines, el órgano jurisdiccional que establece la internación en los términos del art. 34 inc. 1 del CP debe fijar un plazo máximo de duración de la misma teniendo en cuenta cuál pena hubiese impuesto de estar ante una persona con capacidad de culpabilidad.

Habiendo dejado en claro cómo y quién debe establecer el referido plazo, surge la siguiente duda: ¿Exactamente qué implica el cumplimiento de ese plazo?

La respuesta es muy sencilla, una vez vencido dicho plazo la internación involuntaria "medida"- de naturaleza penal perderá dicho carácter -penal-, en consecuencia, de aún existir criterio de internación -lo cual es esperable toda vez que si no median dichos riesgos debería haberse iniciado un proceso de desintitucionalización- deberá continuar dicha internación sólo que su control ya no estará bajo la órbita penal. En consecuencia, ya no se aplicará la excepción contenida en la segunda parte del art. 23 de la LSM, ergo, procederá la "externación automática" contemplada en la primera parte de dicho artículo, toda vez que ya no estaremos en presencia de una internación del art. 34 del CP. 


\section{C.- El incumplimiento de los estándares reseñados. La situación de las personas con declaración de inimputabilidad en la Provincia de Buenos Aires}

Habiendo establecido cuáles son los estándares que surgen del derecho positivo, es momento de realizar un contraste entre los mismos y la realidad que atraviesan las personas con declaración de inimputabilidad en la Provincia de Buenos Aires. A estos fines se tendrán en cuenta los datos publicados por la Defensoría de Casación de la Provincia en función del relevamiento efectuado por el Programa de Salud Mental de dicho órgano. ${ }^{25}$

\section{c.1.- Personas alojadas en establecimientos penitenciarios}

Para comenzar, es menester señalar que del relevamiento efectuado por el referido programa surge que a enero del 2017 en la Provincia de Buenos Aires existían 133 personas privadas de su libertad en establecimientos penitenciarios con declaración de inimputabilidad -art. 34 inc. 1 del CP.

Vale decir, que aunque esas unidades penitenciarias -puntualmente la UP 34 y los pabellones psiquiátricos de la UP 10 y 45, todas ellas sitas en la localidad de Melchor Romerotengan ciertas adaptaciones o particularidades dirigidas a ofrecer una mayor contención a las personas con padecimientos mentales aunque en los hechos las mismas prácticamente se reducen a la presencia de un mayor número de profesionales de la Salud Mental que en una UP ordinaria-, ellas están lejos de cumplir con los estándares citados, es decir, están lejos de ser hospitales -mucho menos generales-

En ese sentido se impone manifestar que: se trata de instituciones que no se encuentran dentro de la órbita del Ministerio de Salud -autoridad de aplicación de la LSM ${ }^{26}$, la mayoría de los profesionales que se encuentran en contacto con las personas allí alojadas -e inclusive sus directores/as- son agentes del Servicio Penitenciario, es decir, personas que no tienen formación en la materia y la arquitectura de las mismas se corresponde a las de una cárcel y no a las de un hospital, lo cual tiene no pocas consecuencias prácticas, a saber: Presencia de celdas de aislamiento, gran número de puertas cerradas con candados -unas cinco- que separan los pabellones donde se alojan los detenidos del área de salud propiamente dicha, etc.

En resumen, se trata de 133 casos en los que se violan los reseñados estándares emergentes del CP, LSM y "Reglas Mandela" referentes al lugar donde deben llevarse adelante las internaciones involuntarias por razones de salud mental. Además, la situación descripta indirectamente resulta violatoria de otros estándares mencionados al importar un obstáculo

25 Los datos aquí citados se encuentran publicados en el lnik titulado: "Inimputabilidad y Salud Mental. La aplicación de la Ley 26657 en el ámbito penal. Primera presentación del taller. 16 y 23 de marzo de 2017. Mar del Plata. Presentación de la Defensoría de Casación” que puede hallarse en: http://www.defensapublica.org.ar/menu_varios.aspx?op=Salud\%20Mental\$]/categoria[@nombre=\$Document os\%20de\%20trabajo\$]\& titulo=Salud\%20Mental:\%20Documentos\%20de\%20Trabajo

26 Las Unidades Penitenciarias de la provincia de Buenos Aires se encuentran en la órbita del Ministerio de Justicia, organismo que resulta ajeno y extraño a la regulación contemplada en la LSM. 
para la finalidad terapeútica de la internación y al encontrarse en las antípodas de la opción menos restrictiva de derechos aplicable a estos casos.

\section{c.2.- El denominado "riesgo social"}

Del señalado relevamiento también surge que existían -a la fecha de la concepción del mismo- unas 20 personas -dentro de las referidas 133-que además de estar alojadas en unidades penitenciarias por razones de salud mental, lo estaban a pesar de no existir criterio de internación -riesgo cierto e inminente del art. 20 de la LSM-, fundando la continuidad esa medida únicamente en el llamado "Riesgo Social", es decir, en la falta de red de contención familia contenedora, obra social, trabajo, lazos sociales, medios económicos para asegurar la subsistencia- en el afuera que le permita viabilizar una externación.

Dicha situación, además de resultar una violación a los estándares desarrollados en relación al criterio de internación, se encuentra expresamente prohibida por el art. 15 de la LSM que al abordar las internaciones manifiesta que “...En ningún caso (...) puede ser indicada o prolongada para resolver problemáticas sociales o de vivienda...” y en consecuencia, establece en sus arts. $15 \mathrm{y}$ $18^{27}$ la facultad/deber en cabeza de los jueces de instar al Poder Ejecutivo -Autoridad de Aplicación de la LSM- a realizar las gestiones necesarias para que se incluya a estas personas en los programas y/o dispositivos correspondientes. Lo cual se corresponde con las obligaciones que establece en cabeza de la Autoridad de Aplicación en su art. $11^{28}$.

Para terminar con esta temática resulta oportuno destacar que, en caso de no existir dichos dispositivos en virtud del juego de lo establecido en dichos artículos -11, 15 y 18 de la LSM-, el magistrado bien podría instar al ejecutivo a fin de que cree los mismos. Postura que se ve fortalecida si se tiene en cuenta lo establecido en el Decreto Reglamentario de la LSM 603/2013, que al abordar el art. 11 de la LSM establece:

La Autoridad de Aplicación promoverá que la creación de los dispositivos comunitarios, ya sean ambulatorios o de internación, que se creen en cumplimiento de los principios establecidos en la Ley, incluyan entre su

27 LSM art. 15:”En ningún caso la internación puede ser indicada o prolongada para resolver problemáticas sociales o de vivienda, para lo cual el Estado debe proveer los recursos adecuados a través de los organismos públicos competentes.” LSM art. 18:”...En caso de que la prolongación de la internación fuese por problemáticas de orden social, el juez deberá ordenar al órgano administrativo correspondiente la inclusión en programas sociales y dispositivos específicos y la externación a la mayor brevedad posible, comunicando dicha situación al órgano de revisión creado por esta ley."

28 LSM Art. 11. - La Autoridad de Aplicación debe promover que las autoridades de salud de cada jurisdicción, en coordinación con las áreas de educación, desarrollo social, trabajo y otras que correspondan, implementen acciones de inclusión social, laboral y de atención en salud mental comunitaria. Se debe promover el desarrollo de dispositivos tales como: consultas ambulatorias; servicios de inclusión social y laboral para personas después del alta institucional; atención domiciliaria supervisada y apoyo a las personas y grupos familiares y comunitarios; servicios para la promoción y prevención en salud mental, así como otras prestaciones tales como casas de convivencia, hospitales de día, cooperativas de trabajo, centros de capacitación socio-laboral, emprendimientos sociales, hogares y familias sustitutas. 
población destinataria a las personas alcanzadas por el inciso 1) del artículo 34 del Código Penal, y a la población privada de su libertad en el marco de procesos penales.

Por otro lado, la vaguedad con la que ambas normas -LSM y el Decreto 603/13- definen mediante ejemplificación- qué debe entenderse por "dispositivo específico", hacen que dicha orden -la de construir un dispositivo para un caso- no resulte tan faraónica o utópica como podría sonar en un primer momento ya que el mismo bien puede limitarse al redireccionamiento de recursos -principalmente profesionales- de parte del Ministerio de Salud, a fin de que proyecten y desarrollen una estrategia de desinstitucionalización que permita cristalizar los estándares de la LSM en el caso en particular.

\section{c.3.- Desproporción}

Otro de los supuestos de violación a los estándares analizados se da en los casos en donde se extralimitó el tiempo durante el cual, según la analizada construcción pretoriana, puede subsistir una internación involuntaria de naturaleza penal.

En ese sentido puede señalarse que se relevaron que de las 133 personas alojadas en unidades penitenciarias en el marco del art. 34 inc 1 del CP:

I.- En 28 casos la privación de la libertad superó el máximo de la pena que podría haberse impuesto en caso de tratarse de una persona con plena capacidad de culpabilidad.

II.- En 27 casos la privación superó el término para acceder a la libertad condicional que hubiera correspondido de haberse impuesto el referido máximo de pena.

III.- En 19 casos la privación superó el mínimo de la pena que podría haberse impuesto.

Como puede advertirse, en los supuestos I y II, evidentemente se violó el estándar establecido por la CSJN ${ }^{29}$. Mientras que en los supuestos contemplados en la categoría III, deberá observarse cúal es el plazo máximo de duración de la internación involuntaria que, conforme "Antuña", estableció el órgano que determinó dicha internación -si es que lo hizopara saber si se ha violado o no dicho estándar.

Conforme se dijo, en estos supuestos -principalmente I y II- en los que se violó dicho límite corresponde que cese en forma inmediata la intervención de la justicia penal, con todo lo que ello importa.

29 A estos fines debe tenerse particularmente en cuenta que en "RMJ" se había superado el término de condicional y no el máximo de pena que podría haberse impuesto. 


\section{D.- Conclusión}

De los desarrollos efectuados a lo largo del presente surge que en la medida que la LSM es aplicable a los supuestos del art. 34 inc. 1 del CP, es imperioso que en esos casos se adecuen las prácticas a los los estándares establecidos por dicha norma -LSM-. Sin embargo, el contraste de esos estándares con los datos obtenidos en relación a las personas con declaración de inimputabilidad en la provincia de Buenos Aires torna evidente que el cambio de paradigmas que propone dicha ley está lejos de verse cristalizado en los hechos. 


\section{Bibliografía}

Congreso de la Nación Argentina. (2010) Ley de Salud Mental N 22.914. En línea en: http://servicios.infoleg.gob.ar/infolegInternet/anexos/175000-179999/175977/norma.htm

Código Penal de la Nación Argentina. (1984). Ley 11.179 En línea en: http://servicios.infoleg.gob.ar/infolegInternet/anexos/15000-19999/16546/texact.htm

Martínez B. M. Derecho y Salud Mental. Editorial Juris. Buenos Aires.

Naciones Unidas. (1977). Reglas mínimas para el tratamiento de los reclusos. En línea en: http://www.ohchr.org/SP/ProfessionalInterest/Pages/TreatmentOfPrisoners.aspx

Rodríguez, J. A., Comentarios a la ley de salud mental. En línea en: http://www.bibliopsi.org/docs/materias/obligatorias/CFP/juridica/sarmiento/rodriguez\%20 -\%20comentarios\%20a\%20la\%20ley\%2026657.pdf 